\title{
A TOP-DOWN BIOMIMETIC DESIGN PROCESS FOR PRODUCT CONCEPT GENERATION
}

\author{
I. LÓPEZ FORNIÉS \& L. BERGES MURO \\ Department of Design and Manufacturing Engineering, Zaragoza University, Spain.
}

\begin{abstract}
There are solved functions in nature that can be used as a basis for novelty in products with a high potential for innovation. This paper shows an alternative methodology of product conceptualization based on biomimetics. Known methods based on functional analysis and creative tools are discussed and related to the proposed methodology. Biomimetics provides new solutions to be applied to product design, making it more creative and original, with innovative features drawn from analogies in nature.

Functional research aimed at product innovation can take advantage of the biomimetic approach, incorporating it into the design process and gaining from it new formulae and methods in the search for functions that are distinctive solutions. The improved methodology is obtained through the integration of intermediate phases in the design process, establishing criteria in the search of key functions, and then applying biomimetics research to find natural solutions. Some conceptual projects have been carried out to test the new design methodology. Keywords: biomimetics, conceptual design, creative tools, design process, functional research, product innovation.
\end{abstract}

\section{INTRODUCTION}

There are several design methodologies using analogy, imitation, translation, copying, or inspiration from nature to find appropriate solutions to today's problems, whether they are functional, structural, based on new materials or sometimes linked to a form or a specific aesthetic.

All of these methodologies are valid under certain circumstances and environments, but future scenarios for innovation will demand new ways of working, combining several methods or tools. In the words of Knut Drachsler [1], project leader at the Fraunhofer Institute IPA, 'Conventional methods of product development are often not sufficient in relation to the demands of innovation. This is where nature with its infinite variety of solutions can be a model for technology - and therefore may be essential to lay the basis for the development of bionic products'.

We must also consider those methods based on emulation, abstraction, and intuition, even if they do not have the same scientific rigor and the results are not always justified. These include cases in which, by evocation, nature may have had some influence but magnifying their contribution detracts from the achievements of the engineering involved [2].

Nature does not have to be copied. It is more helpful to understand and apply its expertise to solve our needs. Wirkkala [3] was very inspired by nature in his work: 'copying nature is an act of manual skill that does not only help to understand things. Studying the structure and evolution of natural objects can even help to understand the world itself'. It is therefore necessary to make the effort to understand the genius of nature and apply this understanding to industrial design processes through biomimetics.

Biomimetics can be seen as part of humanity's attempts to supersede our present achievements due to a natural need to discover, create, and perfect our environment, our safety, our tools, etc. Natural wisdom offers good solutions. By not looking at nature's development of functions, systems, organs, structures, or materials, we are limiting the possibilities of improving our products [4]. Mankind seeks and causes changes, is a precursor to innovation, and takes nature as a reference, even if we know that the product currently being designed does not exist in nature.

(C) 2012 WIT Press, www.witpress.com

ISSN: 1755-7437 (paper format), ISSN: 1755-7445 (online), http://journals.witpress.com

DOI: $10.2495 / \mathrm{DNE}-\mathrm{V} 7-\mathrm{N} 1-27-48$ 
Biomimetics should be used to improve the design process as a complementary method. Its use as a creative resource has been identified for its potential shown in combination with other design methodologies [5]. There is critical thinking about how to develop industrial projects on the back of nature, without necessarily observing already developed intelligent solutions [6].

Biomimetic design is not commonly applied in industrial design since there is no clear methodology; a new methodology that can be used in design and product development may have profitable applications.

This paper presents a biomimetic design process illustrated with a case study in which the learning of the new methodology is achieved by practitioners [7].

\section{BIOMIMETICS IN PRODUCT INNOVATION}

Studies may be carried out into industrial sectors or product groups in which to develop innovation, and such innovation can be applied by systematic improvement of functions identified through functional analysis techniques [8]. These techniques may uncover very specific functions and do not merely point to an intuitive determination of functions in general.

Bionics and biomimetics can bring new solutions to the field of industrial design. Biomimetics is useful and successful in finding inspiration for problem solving design [9], from the simplest ones such as diving fins to the most complex such as the imitation of composite materials.

Several tables, databases, and lists of principles which provide analogies, similarities, or relationships between features of nature and what man can apply to artificial devices have been created [10, 11]. All these tables have in common the pursuit of excellence to transcend state of the art technology.

Biomimetics is applicable in many ways, to innovation in general and to product design in particular [12]. Innovation is possible due to the integration of biomimetics into the design process as part of a methodology at different levels, from the elementary, through assimilation of form or geometry, to the most complex and sophisticated, such as detection systems and decision making through artificial intelligence.

Research paves the way for innovation. The possibility of assimilating effective and optimal results from nature generates knowledge and technological progress to create new applications and especially options for development. In many cases the examination of a living being leads to the learning of a basic principle that can be applied to multiple products through an adaptation process. A good example is the study of shark skin that has generated multiple applications in different environments through its characteristics of creating a dry layer, non-proliferation of bacteria and microorganisms, and reduction of friction to create swimwear and underwater waterproof fabrics or plastic films with antibacterial micro-structures that can be used for protective casings for medical instruments and equipment $[13,14]$. Nevertheless, innovation can also be achieved by the search for as yet undefined new product features, functions that do not arise intuitively [8] but are the result of a creative process.

Functions developed by nature for a specific purpose may have a different application in manmade devices. This is precisely the valuable feature of biomimetics, the ability to extract a principle from a given natural environment and extrapolate it to the artificial.

Functional analysis of objects allows the search for new product concepts. Nature can provide a direct response or be an influence in the development of a new application, so creativity, functionality, and nature come together to create new product ideas.

In processes aiming to achieve solutions based on nature, the definition of functions may respond to specific product design needs. On the other hand, it is possible to identify other functions that are of great interest in nature and may constitute new product applications, those that can potentially generate innovation. 
3 BIOMIMETICS AND DESIGN METHODS

Integrating the study of nature into the conceptualization of products is not a novelty. There are many examples in design history, but not all of them have been achieved by a method. A method marks a path in establishing a set of rules for obtaining an established objective that cannot be affected by chance or fate [15]. The development of a methodology in which we can study and explore new tools and methods enables us to ensure control of the design process.

The known methods of work in bionics or biomimetics can be grouped into two major groups, as shown in Fig. 1. Those which derive from biology to solve a design problem are indirect design processes; and those that start with a design problem and use nature's successes to solve the problem are direct design processes [16].

The first group takes a successful solution from nature to develop and transform it into scientific knowledge of added value that can be applicable to solutions in the artificial environment. This methodology points directly to the design application, showing the feasibility of being applied to a product. Searching for ideas is not only exploratory; ideas must also be valid. Therefore it is necessary to know first the categories in which the design project is framed; second, the classification based on the relationship with the living being; and third, the observed characteristics.

This type of approach goes a step further, arguing that the creative aspects can be related to inspiration, called the trigger for creativity, but defines and includes other categories such as partial or total imitation, e.g. imitation of a function or the use of a mechanism or isolated system. All of these categories relate the project needs to an existing feature in nature that is successful.

An example of application of this methodology is the BIODESIGN PROCESS [17], proposed by Lodato, in which selecting some organism characteristics that supersede current technological possibilities leads to bionic research that identifies and obtains the principles and processes that provide this superiority. Once these characteristics are known, methods and models are developed to describe biological systems in useful terms for designers and to select those that demonstrate the feasibility of translating this knowledge into a safe and effective device.

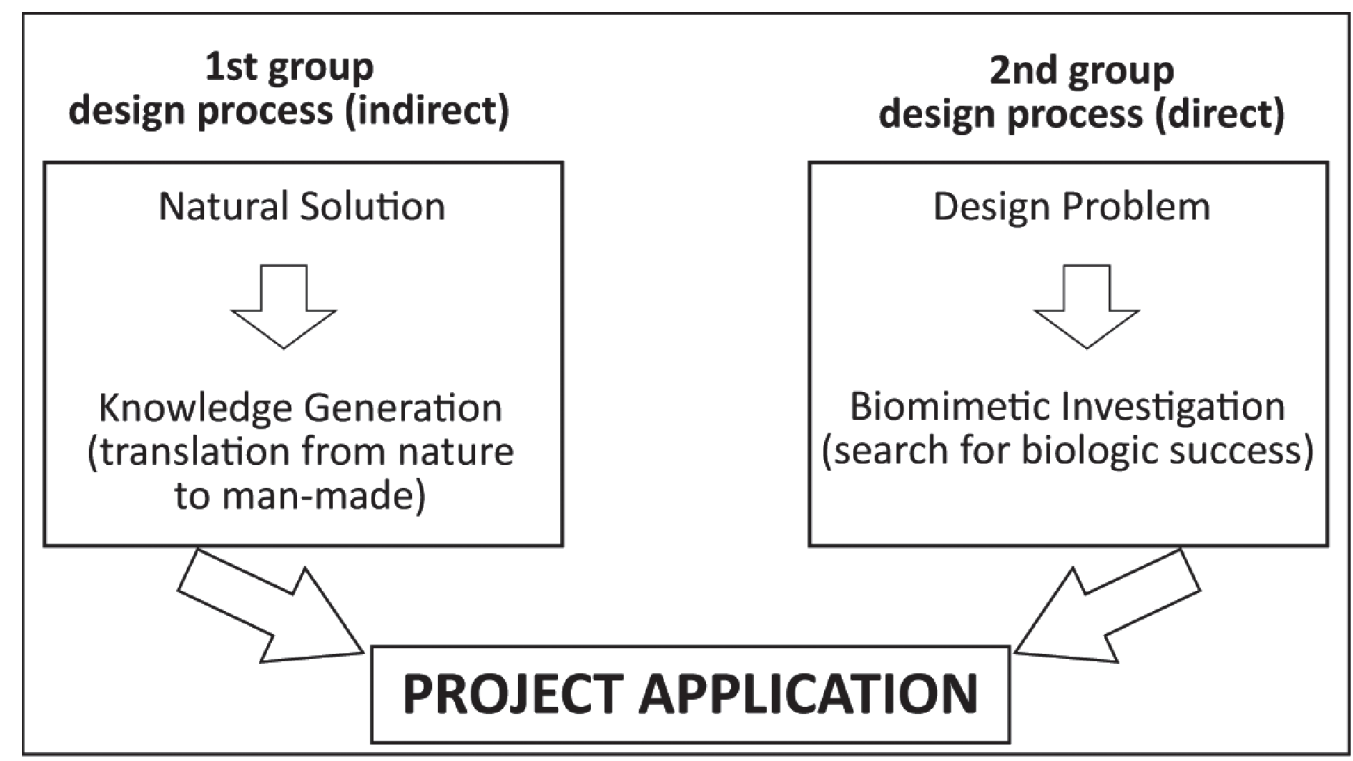

Figure 1: Design processes that involve biomimetics. 
Similar processes of work have been developed by Vincent and The Biomimicry Institute. Vincent [11] uses databases with examples from nature and a method related to TRIZ, which is called BIOTRIZ. These methods try to normalize and standardize the process. Biotriz is seen as a systematic tool used to solve technical problems. Solutions are based on analogies like those found in nature, in the natural patent database as described by their creators.

The Biomimicry Institute [18] states that biomimicry is a tool for innovation, helping innovators from all areas of life, engineers, designers, architects, business leaders, among others, to use biomimetics as a tool to create more sustainable designs. The biomimetic process described in the design spiral can serve as a guide to help innovators to overcome a challenge by means of nature, and refers to the natural world for inspiration to assess and ensure that the final design mimics nature at every level, form, process, and ecosystem.

The second group works with a methodology that after defining a problem in engineering or design, it carries out biological research trying to find principles that can be extrapolated for solving problems. There are no references relating to researchers working exclusively with this methodology; usually those who work with this method also employ the working method of the first group.

There are multiple references to the works of Bombardelli and Di Bartolo (et alters) [19, 20, 21] at the Department of Bionics of the European Design Institute in Milan whose projective theories are considered analytically accurate.

Gester in 'Integrating biomimicry in product development' [22] explains the methodology used at the University of Freiburg by Milwich and Speck [23]. The approach taken to perform biomimetics is to carry out basic biological research in biomechanics and functional morphology, and then to take the new knowledge and put it at the disposal of technology processes; this is known as the 'Bottom-Up' process. In addition, an alternative strategy is followed consisting of the search for possible solutions from the biological model to solve specific technical problems; the process is called 'Top-Down'.

The top-down process begins with the detection of a technical problem that can be solved through the implementation of a design process based on biomimetics. The process continues formulating the technical problem, searching for analogies in biology, identifying the relevant principles, making abstractions of the biological model and application of the technology through prototyping and testing. The bottom-up process begins with the identification of a biological system that offers an opportunity to develop a principle, function, material, etc. It poses possibilities for innovation or improvements on what already exists through the identification of a biological system that analyzes biomechanics, functional morphology, and anatomy to understand the essential principles of the biological model and which could be applied to technology through prototyping and testing.

Another similar example of an application of the two methods is that of Helms at the Center for Biologically Inspired Design. Their study [24] has established a new methodology for the development of biologically inspired design projects, setting improvements in the design process.

The problem-driven process is developed by defining the problem and its reformulation to find and define the biological solution from which to extract the biological principle. This process is based on the definition of the problem by means of two techniques, functional decomposition and functional optimization.

Moreover, the solution-driven process begins with a biological solution, which is extracted first, studied in depth, and then technical problems are found for the principle to be applied, as seen in the methods of the first group.

The poor definition of problems, for both processes, implies that the application of the natural principle at the last stages may not be appropriate, leading to a misunderstanding and wrong 
redefinition of the principle found in nature. This type of situation leads to one of the most common problems in innovation and design, and by analogy in creativity, the reduction of uncertainty.

For this reason, these types of processes related to biomimetics, are not intensively used. These processes are exploratory; the end result is no guarantee of success. On the other hand, these processes may provide innovative solutions that can result in obtaining original solutions, representing advantages over others such as normative processes.

Both processes are valid and have in common the fact that interdisciplinary collaboration is needed between technology and biology for their development [23]. This is difficult to achieve for both the expert biologist and the engineer. It is not easy to find a specialist that can apply the results of each process, and it is difficult to find appropriate information in the right format and the appropriate language [20].

To try to overcome these difficulties, communication tools and mechanisms are being developed by researchers [22]. The first, being developed by the Tribology Center for Biological Surfaces at the Max-Planck Institute [25], is based on the Cambridge Materials Selector system [26] with a database of biological materials with their characteristics and appropriate definitions for use in specific applications.

A second tool is based on TRIZ, which interprets nature as a large database of natural patents [11]; there are databases of biological principles that allow the extraction of functions, materials, structures, and mechanisms that may provide solutions for the technical problems in engineering.

A third tool uses a lexical search based on keywords. The search is carried out in biology textbooks that match biology terms with those that can define a technical problem in engineering. This is a simple, easy to apply, and fast method but it is necessary to correctly define the engineering terms, and it also depends on the availability and quality of biology texts found.

\section{FUNCTIONS, FUNCTIONAL ANALYSIS, AND CREATIVITY}

Products are the sum of their functions. They are designed to cover a necessity that is represented by their main function, but there are other features that complement or enhance their development. All products can benefit from functional analysis for better design and quality improvement [8]. Methodical and exhaustive functional analysis gives the product a level of functional quality that places it ahead of its competitors.

Creativity and innovation play a key role in industrial development, but the new products resulting from these should always offer more satisfaction to the user, or match as closely as possible their needs or desires.

\subsection{Function definition}

Function definition responds to the satisfaction of a number of customer needs. Innovation seeks alternatives to existing functions and tries to find new ways to perform these functions. Moreover, new features that do not yet exist in products are sought to generate new product concepts. Such functions existing in nature have a commercial interest [27], and an understanding of the functions provided by beings and processes found in nature can guide us to imitate and produce nanomaterials, nanodevices, and new processes.

About $60 \%$ of functions are defined intuitively from existing knowledge and past experiences. This is not enough: there are a substantial number of functions that are not yet covered or defined.

Innovation could be developed by applying undetected functions to products that are similar in nature [28], especially in terms of exoskeleton casing relationships [9]. The functional analogy between casings, shells, and exoskeletons should be mentioned as a key factor in research. 
The function of the biological system can be defined as the action required to achieve a useful or desired future condition [10]. In technical systems, achieving the goal of the biological system is delegated to a technical device. The goal remains the state of the system in the future. Thus, the function of a technical system is the action needed to achieve the useful or desired future condition with the help of a technical device.

Therefore, it can be said that to achieve a new feature in a product it is necessary to determine the function that is analogous to a living being and consider our product as a living being, implementing this function. Bogatyreva provides a table of functions that is hierarchically classified and organized in different levels, from the most generic to most specific (see Table 1) [29]. The 'Program functions' are generic and do not resolve the ultimate goal of the product. The 'Goal functions' are necessary to ensure compliance with the goal. 'Specific functions' are those that allow the 'Goal functions' to be met.

In works previous to the development of this design methodology, tables were made relating specific features of an object with natural solutions. They were represented by a 'mirror table' with organized hierarchies, see Table 2 . The similarity with the work of other researchers is shown in an example table, see Table 3. The mirror line establishes the division from what exists in nature and

Table 1: Classification of biological functions applicable to technical solutions through biotriz.

\begin{tabular}{lll}
\hline Program functions & \multicolumn{1}{c}{ Goal functions } & \multicolumn{1}{c}{ Specific functions } \\
\hline Create & Reproduce & Multiply, Imitate, copy, etc. \\
& Produce & Increase, emit, generate, etc. \\
& Grow & Increase, assemble, accumulate, etc. \\
& Deposit & Increase, store, save, etc. \\
Make tools & Use nature, modify nature, design, etc. \\
Defend & Clean, protect, resist, seal, etc. \\
Regulate temperature & Heat, cool, freeze, readjust, etc. \\
& Respire & Breathe, ventilate, stabilize, etc. \\
& Feed & Nourish, deposit, etc. \\
& Support & Hold, border, etc. \\
& Insolate & Lighten, darken, ignite, etc. \\
& Osmose & Wet, dry, drink, etc. \\
Feed & Capture, graze, ingest, digest, shred, chop, etc. \\
Destroy & Defend & Stop, beat, attack, etc. \\
& Destruct & Decrease, bend, crack, corrode, erode, etc. \\
Change phase & Melt, freeze, evaporate, crystallize, etc. \\
Transform & Embed/absorb, extract/separate, metamorphose, etc. \\
Transport & Conduct, distribute, deliver, transfer, etc. \\
Move & Migrate & Roll/traverse, vibrate, adapt, fly, burrow, etc. \\
& Locomote & Lift, drop, orient, rotate, etc. \\
& Manipulate & Sense, detect, locate, etc. \\
Inform & Select, behave, response, etc. \\
& React & Sense, detect, measure, etc. \\
\hline & Control & \\
\hline & &
\end{tabular}




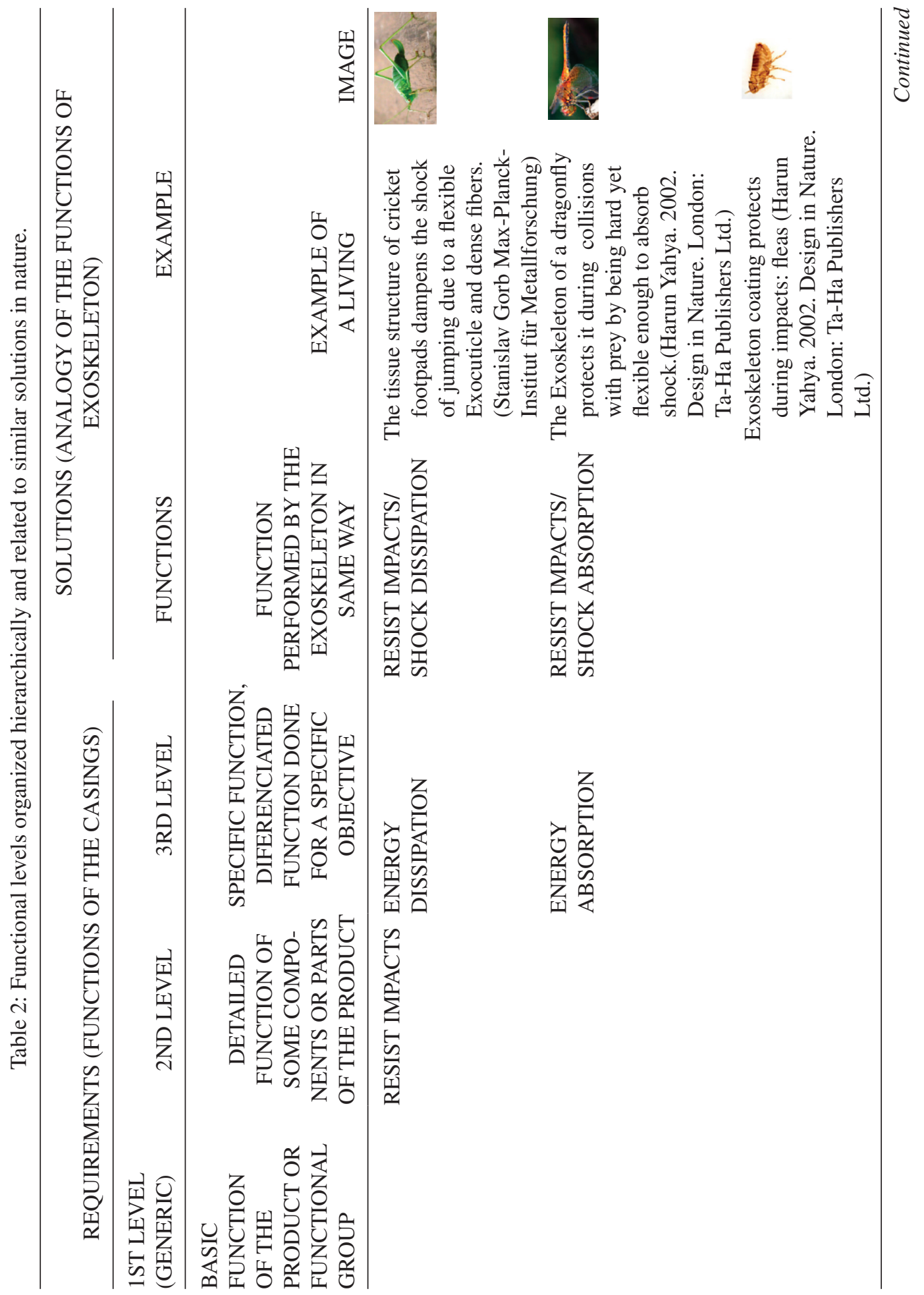


34 I. López. Forniés \& L. Berges Muro, Int. J. of Design \& Nature and Ecodynamics. Vol. 7, No. 1 (2012)

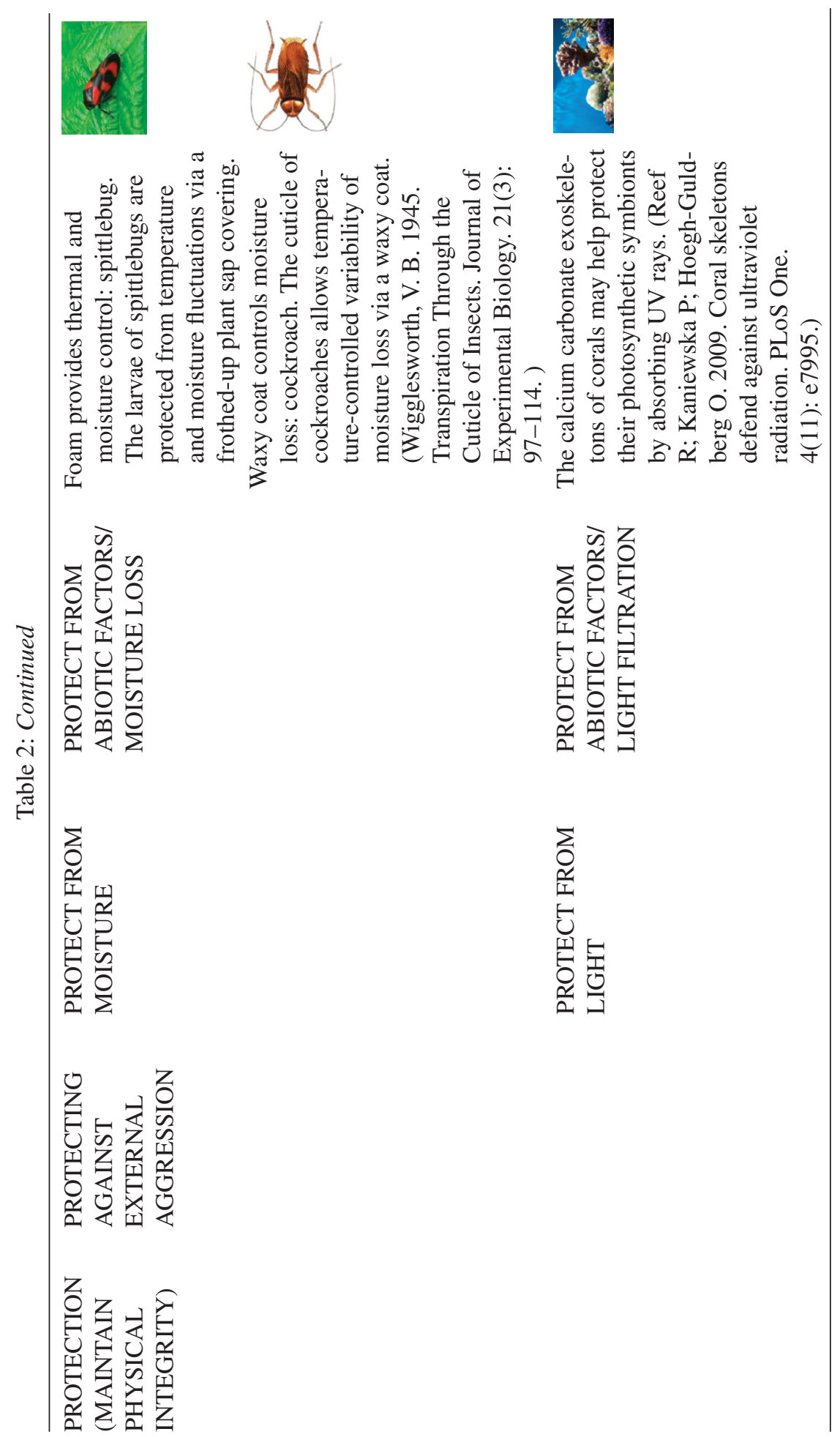


Table 3: Synthesis of methodology tables used by Gruber and Gosztonyi.

\begin{tabular}{|c|c|c|c|c|}
\hline & & Nature & & Man-made \\
\hline \multirow[t]{2}{*}{ Gruber } & Primary function & $\begin{array}{l}\text { Skin functionality in } \\
\text { living organisms }\end{array}$ & By/what & $\begin{array}{l}\text { Architectural } \\
\text { analogy }\end{array}$ \\
\hline & $\begin{array}{l}\text { Function that } \\
\text { exists in a living } \\
\text { being and is } \\
\text { desired as a } \\
\text { solution for a } \\
\text { technical } \\
\text { problem }\end{array}$ & $\begin{array}{l}\text { Lists of functions } \\
\text { performed by the } \\
\text { skin in living } \\
\text { organisms }\end{array}$ & $\begin{array}{l}\text { Who is doing the } \\
\text { function and how } \\
\text { the function is } \\
\text { achieved }\end{array}$ & $\begin{array}{l}\text { Analogies in } \\
\text { the field of } \\
\text { architecture }\end{array}$ \\
\hline Gosztonyi/ & Function & \multicolumn{2}{|l|}{ Biologized questions } & Technical goals \\
\hline Gruber & $\begin{array}{l}\text { Desired function } \\
\text { for innovation }\end{array}$ & \multicolumn{2}{|c|}{$\begin{array}{l}\text { Questions for survey in nature, looking } \\
\text { for the most promising principles } \\
\text { Transition from natural to artificial }\end{array}$} & $\begin{array}{l}\text { Requirements and } \\
\text { state of the art }\end{array}$ \\
\hline
\end{tabular}

Table 4: Finding biomimetic references for key functions.

\begin{tabular}{|c|c|c|}
\hline $\begin{array}{c}\text { KEY FUNCTION } \\
\text { (PROJECT OBJECTIVES) }\end{array}$ & $\begin{array}{c}\text { RESEARCH GUIDELINES } \\
\text { (HOW TO ACHIEVE THE KEY FUNCTIONS) }\end{array}$ & $\begin{array}{l}\text { NATURAL REFERENCE } \\
\text { (BIOMIMETIC RELATION) }\end{array}$ \\
\hline \multirow{7}{*}{ KEY FUNCTION 1} & HOW COULD...? & LIVING BEING 1 \\
\hline & WHO COULD...? & LIVING BEING 2 \\
\hline & WHY SHOULD...? & LIVING BEING 3 \\
\hline & WHAT STRUCTURE COULD...? & LIVING BEING 4 \\
\hline & WHAT MATERIAL COULD....? & LIVING BEING 5 \\
\hline & WHAT IS NEEDED TO ....? & \\
\hline & WHERE COULD .....? & \\
\hline KEY FUNCTION 2 & QUESTIONS FOR KEY FUCNTION 2 & LIVING BEING $X$ \\
\hline KEY FUNCTION 3 & QUESTIONS FOR KEY FUCNTION 3 & LIVING BEING Y \\
\hline KEY FUNCTION 4 & QUESTIONS FOR KEY FUCNTION 4 & LIVING BEING z \\
\hline
\end{tabular}

the corresponding artificial requirement. The evolution of this table leads to the organization of functions based on mind maps and relationships with natural references, as seen in Table 4 . The purpose of the 'mirror table', Table 2, was to identify the most generic functions of the product casing and thus define other functional levels more specifically related to solutions in nature. The table shows the example of protection as a function needed in the product design and protection as performed by natural exoskeletons. 
Other examples of the use of tables to represent a hierarchy of functions in search of biomimetic applications can be seen in summarized form in Table 3 [30, 31]. In these tables it can be seen that the objective is to resolve a function by means of natural solutions, establishing questions and defining references to biological principles that can best be transferred to the predetermined objectives.

Both tables have a characteristic separation between the desired function in nature and intended purpose in the artificial field, in this case the relation being made between skin and building facades.

\subsection{Functional analysis and creativity}

In classical functional analysis by means of functional trees, functional graphics, and the FAST method among others, products can be studied because they already exist, while for the generation of new concept products it is necessary to apply creativity and generate alternative methods. For this reason, the analysis of functions is related to the creativity technique of mind mapping. There is a link between these tools since both of them develop hierarchical organizations which set levels of importance and in some cases of abstraction.

Dr. Tony Buzan, creator of the 'mind maps' method as a learning tool [32], uses it as an effective method for generating ideas by association or analogy. It begins with a central goal, the main idea, and works outwards in all directions, producing a growing and organized structure composed of key words, in our case key functions.

Functional analysis using the functional tree is a growing branch structure, as in mind maps, which associates, organizes, and places functions in hierarchical order.

Figure 2 shows the basic outline tree of functions and the application in a mind map searching for new functions. Analyzing an existing product, both schemes have a common branched structure, ordered by level of importance, which is developed up to a final level. In this ultimate level a function is found. Using functional analysis such as a mind map, when the product does not yet exist or is not even defined, the final level ends in a key feature, and this final level identifies new functions that are called key functions.

In some cases it may occur that functions are related to different levels and between different functional groups. Figure 2 shows with dashed lines the relationships that may have a greater interest. Levels are established from the most generic to the most specific.

On the most generic level, the basic functions lead other functions to a target or feature that distinguishes the product, and this feature is more specifically defined at the end levels. These key functions will be the germ of a possible innovation [10].

Key functions are innovation features that become product functional requirements, both in its main functions and in the secondary or complementary. The goal is to find analogies with the functions in nature [9].

The first level of functional analysis is called the 'functional group'. This is a group of functions with a high degree of necessity. Functional decomposition allows an understanding of a complex function. This function or functional group is achieved through various functions or sub-functions called secondary functions. Biological systems are complex, multifunctional and connected, so it is difficult to isolate a single function [24]. Functional optimization defines a function or group of functions as an equation to optimize the problem [24]. The designer analyzes the possible solutions according to a criterion that assesses the performance of the function with respect to optimization. In biology it is also possible to define equations to find the optimal development of a function, determining the factors that positively or negatively affect the achievement of that function. For example, in the growth of a plant the quantity and quality of nutrients or the quantity and type of solar radiation are factors that provide an optimum when correctly balanced. 


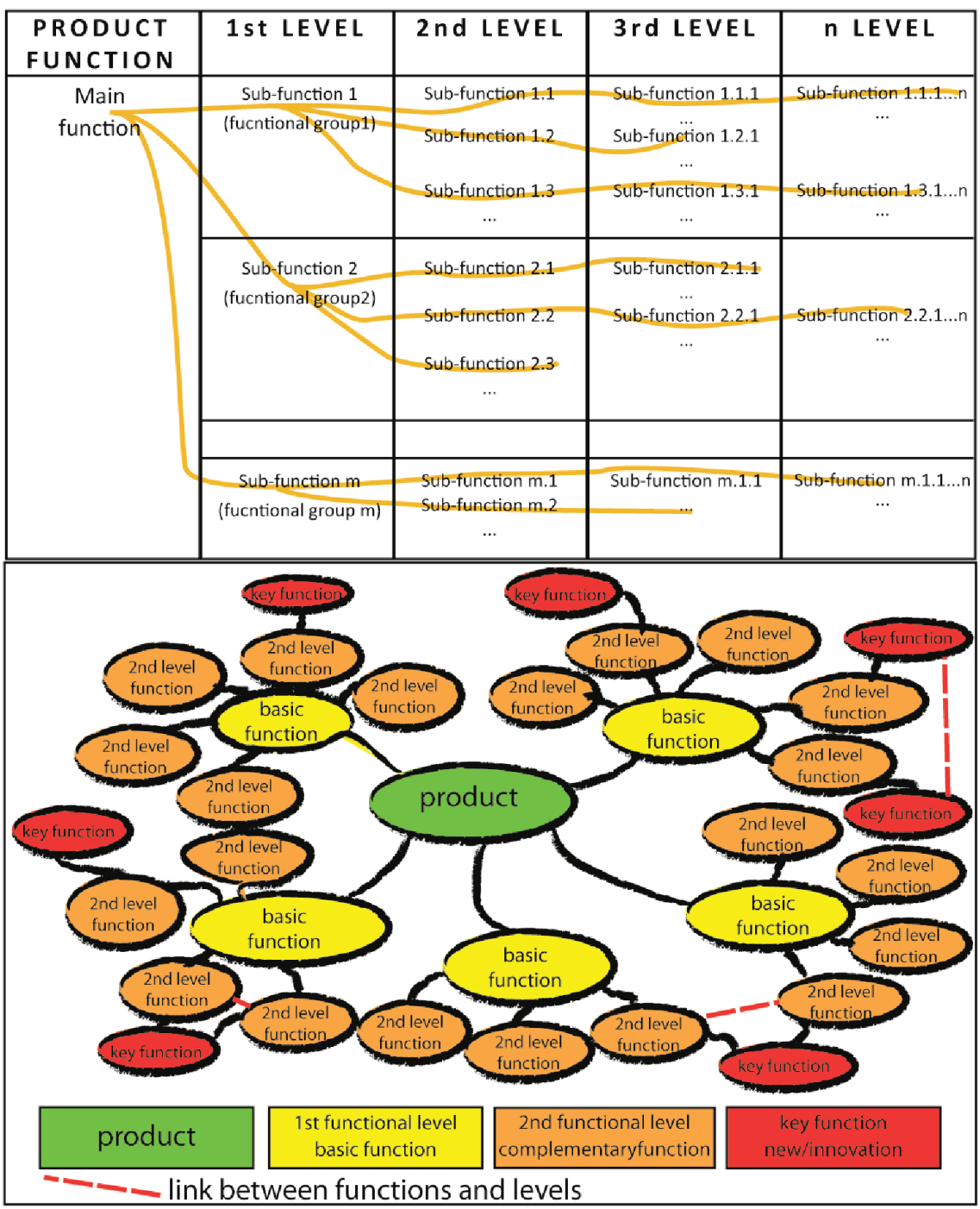

Figure 2: Functional tree and key functions hierarchy in mind maps.

\section{A TOP-DOWN BIOMIMETIC DESIGN PROCESS FOR CONCEPTUAL DESIGN}

A top-down process can be defined as an approach to a problem that begins at the highest conceptual level and works down to the details. The main goal of this work is to establish a new methodology, based on a traditional design process that is structured in phases of analysis and synthesis. A methodology is introduced in which the goal is to find new product concepts, new functional solutions. Figure 3 shows the similarities and differences between the classical and the new method proposed.

The initial phase for both methods is similar. The aim is to define the project to establish the objectives, limitations, and restrictions. In a real project the outcome is a design brief, whereas in our experimental methodology a general framework is set. We select a sector of industry or major product group of common characteristics requiring innovation. 


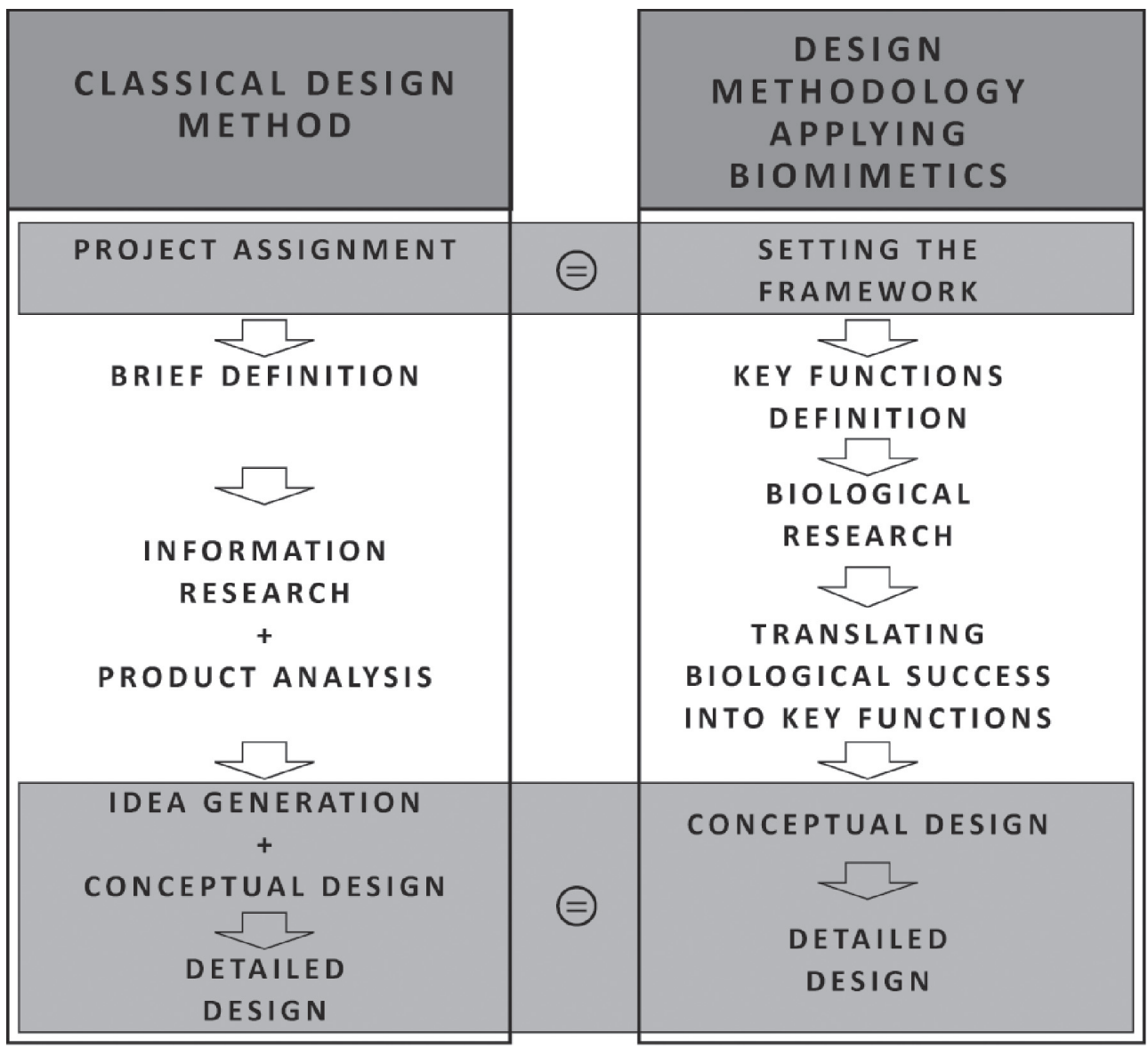

Figure 3: Similarities and differences between the classical and new method.

The design brief will establish the design specifications and product requirements. This is followed by a phase of information and documentation that examines the product design and its state of the art. Analyses are carried out (functional, formal, use and user, ergonomics, materials and processes, etc. ...) to define a set of conclusions that will be a resource for generating ideas in a conceptual phase, then moving into a phase of detailed design.

In the proposed new methodology, after defining the framework, the search for key functions is initiated by using the mind map technique. Then the key functions are listed, see Table 4, and this leads to biomimetic research and the translation of selected successful cases in nature to be applied to the key functions. Once the key functions are settled, the concept and detailed design is implemented, and these final stages are analogous to classical methodologies relating to product formalization.

To develop the biomimetic research, a table with three columns is drawn up. The first column lists the previously defined key functions, the second lists the research guidelines relating to how to achieve the key functions, and the third shows the relation of these guidelines to a living being that may provide a particular solution. Table 4 shows how biomimetic references can be found. 
The table presents a two-way path in which identifying the best solutions from nature that fit the key functions is shown by the orange line. Once a series of natural references are found, the best are chosen for implementing the most suitable solution to our key function, as shown by the green line.

The research guidelines are developed by asking questions about the key functions. These questions are defined in biological terms to translate a technical issue into a biological search [30, 31].

Some projects with common objectives have been developed. In all of them, it has been necessary to show the relationship between natural and man-made environments through existing functions in exoskeletons and casings. These design projects have been undertaken by students who have implemented this new methodology.

\subsection{Objectives}

The development of a methodology to implement biomimetic design is the main objective of this work. This methodology will help designers to identify solutions developed by nature that can be applied to meet product needs and requirements in a better way to achieve innovation [6-7].

Other objectives are:

- To draw analogies between product casings and natural exoskeletons from the functional point of view.

- To understand, analyze, and apply existing methodologies related to biomimetics, and some analyses used in product design such as functional, formal, structural materials, and usage analysis.

- To establish valid sources of information that contribute to biological knowledge, thanks to the analysis carried out in the design process.

- To work with these methods in such a way that the designer becomes familiar with research given that some features and natural solutions can only be found by research.

\subsection{The implementation stages of the methodology}

Every phase is explained in detail and illustrated with examples from projects carried out experimentally.

\subsubsection{Initial phase. Setting the framework}

From past experience it is known that biomimetics can provide project arguments and solutions to proposed problems [9]. At this preliminary phase, the functional requirements are established to obtain improvement and product innovation, and thus a project framework is developed. An initial situation is proposed in which there is no project assignment or specific objectives, so it is necessary to create a framework that sets out the main criteria for selecting the design object. This framework is called the 'project argument'.

In our example, consumer product casings have been chosen due to the fact that they are found with virtually all products. Very often casings serve little purpose but their presence is absolutely necessary, and their functionality can be extended.

On the other hand, there are products which have all their functions contained in their casings, and improvements or innovations might be proposed.

In addition, the 'biomimetic argument' should have a relation with the 'project argument' justified by nature analogies.

Before designing or creating an object one must consider what it would be if it were a living being, how nature would perform a specific function, or to what in nature it can be compared on the basis of having similar functions. 
Figure 4 shows how both the natural and man-made objects are related internally and externally to their environment and how the exoskeleton and casing behave. The living being is characterized by exchange of energy, matter, and information. The product, however, is characterized by its functions, how its shell or casing provides protection and support, allows the exchange of matter and energy, and allows communication. In both cases these are basic functions.

Exoskeletons are the housing of animals and some plants. Invertebrates comprise the most diverse animal group on earth and represent over $90 \%$ of the planet life forms. Their exoskeletons consequently include a large number of functions, some of them basic and fundamental, others specific and with great differences that will make them special for our study.

The casings form a boundary between the functional component of the product and the external environment, as in the living body the skin or exoskeleton is the surface that isolates it from the outside.

Then a list is created of possible products whose casings have certain significance because of their function or an outstanding feature. The products are chosen regardless of the end user or application environment, and therefore there is no limitation for this type of specification. Figure 5 shows a brief list of selected products, as an example.

Looking at this group of products, functions that may be innovative and provide differentiation and added value are selected. The list of features allows us to classify and establish criteria to identify the key functions.

Key features are those that meet functional requirements of a product both in its main features and in secondary or complementary functions; the goal is to find the application criteria that correspond to the natural environment functions.

\subsubsection{Phase 1. Analyzing the key functions}

The potential products in which housing is a predominant factor due to its functionality or physical factors such as weight, volume, and material in relation to the function performed are listed. Those that may have more chances of finding innovative features are taken to create mind maps.

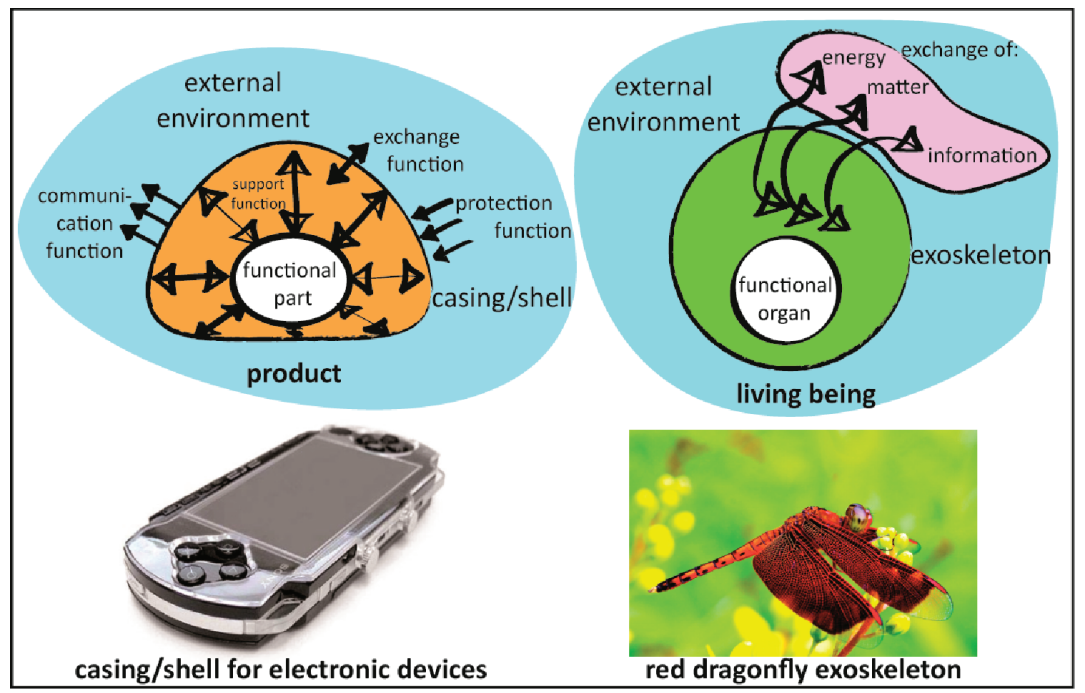

Figure 4: Product and living being relation to external environment through the shell and the exoskeleton. 


\begin{tabular}{|c|c|c|c|c|c|}
\hline $\begin{array}{l}\text { PRODUCT } \\
\text { CATEGORY }\end{array}$ & $\begin{array}{l}\text { Electronic } \\
\text { devices } \\
\text { with } \\
\text { functional } \\
\text { covers, } \\
\text { touch, } \\
\text { etc... } \\
\end{array}$ & $\begin{array}{l}\text { Litter } \\
\text { bins or } \\
\text { recycling } \\
\text { bins }\end{array}$ & $\begin{array}{l}\text { Packaging } \\
\text { for food, } \\
\text { disposable } \\
\text { packs }\end{array}$ & $\begin{array}{l}\text { Elements for } \\
\text { body protection, } \\
\text { helmets, bicycle } \\
\text { or motorcycle } \\
\text { armour, gloves, } \\
\text { boots, goggles } \\
\text { and masks, etc... }\end{array}$ & $\begin{array}{c}\text { Suitcases and } \\
\text { travel bags }\end{array}$ \\
\hline IMAGE & $\frac{1}{2+\infty}$ & & & & \\
\hline
\end{tabular}

Figure 5: List of selected products and examples.

These maps are used to detect 'key functions', which later will be related to solutions taken from natural environment. This is a creative way of organizing and ranking ideas that may arise as functions, unlike other techniques in which the object must be present to be analyzed.

In some cases the functions are related to different levels and between different functional groups. Those functions that are not related to the biomimetic argument are discarded.

Mind maps are used to provide greater creative freedom in the definition of an object or product that does not yet exist. Some of these functions are selected for biomimetic research. Figure 6 shows the mind map technique for a suitcase/backpack in which some key functions, marked in red, have been selected.

\subsubsection{Phase 2. Looking for biomimetic solutions}

Once the key functions have been defined, the research phase starts. At the same time the project is documented with the technology state of the art, looking for the more innovative objects by analyzing the reasons that distinguish them. Furthermore, biomimetic research is carried out to investigate how exoskeletons perform the key functions. Searches are planned by identifying sources of valid information, setting search criteria, and organizing the information [33]. Sources are often specific documentation from specialists, biologists, scientists, and researchers in science museums, and databases or references such as ASK-Nature.org among others [34].

After being chosen, the key functions are transferred to the table in which relations with the natural environment are established. A series of questions are posed to achieve a detailed definition of the key function.

Several natural solutions may refer to the same key function in the table. These are chosen for later development. The criterion for selection is based on the possibility of developing and implementing the product, looking for the viability of the key function. Table 5 shows a table with key functions selected in Fig. 6.

The results vary greatly due to the degree of definition, the validity of the information gathered and the complexity of the subject. Most of the projects achieved good results both in the definition of key functions and in the search of innovative features in biomimetic research.

\subsubsection{Phase 3. Applying the biomimetic solution to the key function}

In this phase the most valid biomimetic references related to the key function are chosen, and there is a development in the opposite direction transferring biological analogies toward applicable 


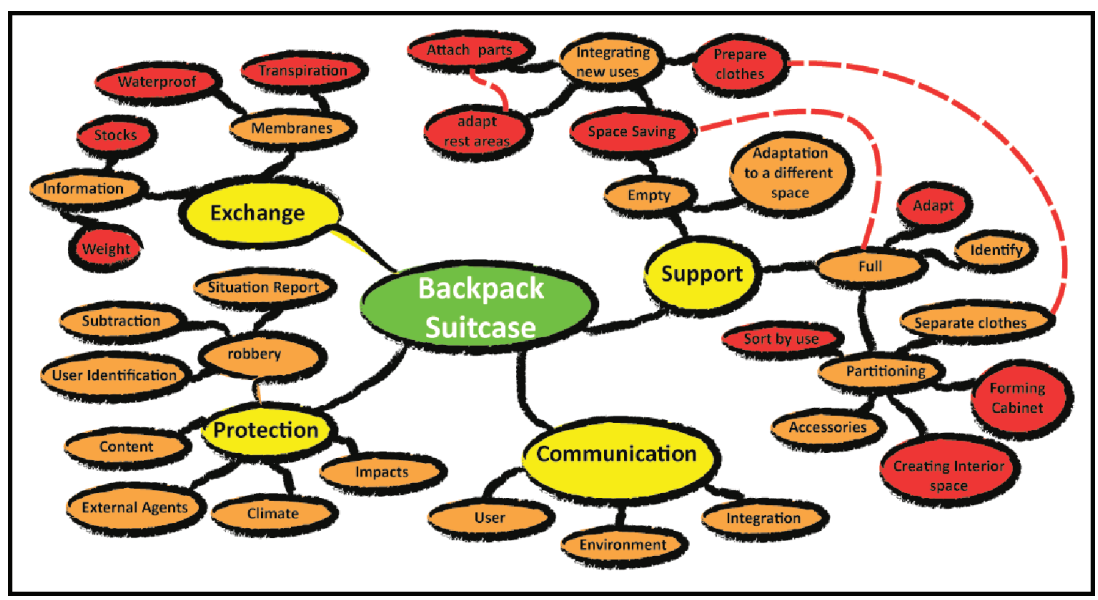

Figure 6: Examples of mind maps and selection of key functions.

Table 5: Finding nature solutions to key functions.

\begin{tabular}{|c|c|c|}
\hline $\begin{array}{l}\text { Key function (Project } \\
\text { Objectives) }\end{array}$ & $\begin{array}{l}\text { Research guidelines } \\
\text { (How to achieve the key } \\
\text { functions) }\end{array}$ & Natural reference (Biomimetic relation) \\
\hline \multirow[t]{2}{*}{$\begin{array}{l}\text { KEEP IN ORDER/ } \\
\text { SORT BY ITS USE }\end{array}$} & Separate membrane & $\begin{array}{l}\text { Palolo Worm. At the breeding season the rear } \\
\text { half of each worm transforms dramatically, } \\
\text { developing fast-growing reproductive } \\
\text { organs. The worm itself reverses its } \\
\text { position within its tube, with its highly } \\
\text { modified posterior half projecting out of } \\
\text { the tube. Once the reproductive organs } \\
\text { are fully developed, the posterior body } \\
\text { half breaks off from the rest of the worm. } \\
\text { (Shuker, KPN. 2001. The Hidden Powers } \\
\text { of Animals: Uncovering the Secrets of } \\
\text { Nature. London: Marshall Editions Ltd) }\end{array}$ \\
\hline & $\begin{array}{l}\text { Separate and grow a bag } \\
\text { (to stretch, shrink, etc.). }\end{array}$ & $\begin{array}{l}\text { Abdomens store nectar: honeypot ants. In } \\
\text { Australia, the honeypot ants collect nectar } \\
\text { and force-feed it to workers of a special } \\
\text { caste until their abdomens are distended to } \\
\text { the size of peas and their skins stretched so } \\
\text { thin that they are quite transparent. } \\
\text { (Attenborough, D. 1995. The Private Life of } \\
\text { Plants: A Natural History of Plant Behavior. } \\
\text { London: BBC Books.) }\end{array}$ \\
\hline
\end{tabular}


Table 5: Continued

Protect bacteria (no growth promoting conditions)

Small units forming a variable larger unit

Quick access to desired areas

\section{ADAPT REST AREAS}

ADAPT FORM
Soft areas for support Inflatable areas (pockets of air, water, etc.)

Expand support structure.

Stretch, be flexible
An engineered surface microtopography based on the skin of sharks, Sharklet AF ${ }^{\mathrm{TM}}$, has been designed on a polydimethyl siloxane elastomer PDMSe to disrupt the formation of bacterial biofilms without the use of bactericidal agents. Sharklet Technologies, LLC

Red and green algae (kelp) are able to stabilize a normally reactive compound called bromine in a way that fends off microbes without harming the alga

Leaf-cutter ants of genus Atta (atta, eciton, or quisonde) - its jaw sutures and disinfects using formic acid. (Pallasmaa, J. 1995. Animal architecture. Helsinki: Museum of Finnish Architecture.)

Fractals are considered a deep pattern in nature. They closely align with a number of Life's Principles, especially 'Cellular and Nested'

The joints of some arthropods have two degrees of bending freedom (up-down and left-right) thanks to two one-degree bending joints found at right angles to each other

Sea sponges

Venom bags. Fish eggs. Honeypot ants

Arterial walls resist stretch disproportionately: cephalopods

Extension in spider legs was hydraulic, not muscular or elastic

Supportive gel enables extreme shape change: sea anemone. The supportive gel-like substance (mesoglea) of sea anemones allows extreme shape changing due to its viscoelasticity. (Steven Vogel. 2003. Comparative Biomechanics: Life's Physical World. Princeton: Princeton University Press.)

flexible exoskeleton. Abdomen of insects and their muscle groups, such as beating of the wings of a fly, internal contractions of the exoskeleton, and exoskeleton elasticity in dragonflies (Harun Yahya. 2002. Design in Nature. London: Ta-Ha Publishers Ltd)

Palolo Worm 
Table 5: Continued

\begin{tabular}{|c|c|c|}
\hline & Change shape & $\begin{array}{l}\text { Similarly, the uterus of female mammals } \\
\text { must expand and contract with gestation } \\
\text { and birth, often an order of magnitude } \\
\text { (tenfold). The hooped fibers of chitin in the } \\
\text { locust are paralleled in the interior circular } \\
\text { muscle fibers of the uterus } \\
\text { Shell changes shape. The shell of the pancake } \\
\text { tortoise allows it to wedge into small spaces } \\
\text { by being flexible at the bridges. (Fowler, } \\
\text { ME; Miller, RE. 2003. Zoo and Wild Animal } \\
\text { Medicine. Philadelphia: W.B. Saunders Co) } \\
\text { Body changes shape: sea anemone. The cen- } \\
\text { tral cavity of sea anemones is reinflated by } \\
\text { water pumping in at low pressures thanks to } \\
\text { ciliary pumps. (Steven Vogel. 2003. Compar- } \\
\text { ative Biomechanics: Life's Physical World. } \\
\text { Princeton: Princeton University Press) }\end{array}$ \\
\hline & Elastic response & $\begin{array}{l}\text { Leaves have elasticity, shape memory: } \\
\text { resurrection fern. Leaves of the resurrection } \\
\text { fern regain shape after dehydration due } \\
\text { to hierarchical structure of palisade and } \\
\text { spongy layers }\end{array}$ \\
\hline \multirow[t]{2}{*}{ SPACE SAVING } & Expand protective structure & $\begin{array}{l}\text { Wings are deployable: beetles. The beetles } \\
\text { protect their delicate wings by turning the } \\
\text { front pair into stiff thick covers, which fit } \\
\text { neatly over the top of the abdomen. The } \\
\text { wings are stowed neatly beneath, carefully } \\
\text { and ingeniously folded. The wing veins } \\
\text { have sprung joints in them. When the wing } \\
\text { covers are lifted, the joints unlock and the } \\
\text { wings spring open. (Attenborough, D. } 1979 . \\
\text { Life on earth. Boston, MA: Little, Brown } \\
\text { and Company.) }\end{array}$ \\
\hline & $\begin{array}{l}\text { Expand protective } \\
\text { membrane }\end{array}$ & $\begin{array}{l}\text { Deployable web distracts predators: blanket } \\
\text { octopus. The membrane attached to some } \\
\text { arms of the blanket octopus serves as a } \\
\text { defence mechanism because it expands } \\
\text { to distract predators and can be shed if } \\
\text { necessary. (Nixon, Marian; Young, John } \\
\text { Zachary. 2003. The Brains and Lives of } \\
\text { Cephalopods. USA: Oxford University } \\
\text { Press) }\end{array}$ \\
\hline
\end{tabular}


Table 5: Continued

\begin{tabular}{|c|c|c|}
\hline & Collapsed to protect & $\begin{array}{l}\text { Pangolin. Scales of pangolins provide } \\
\text { flexibility yet strong protection by } \\
\text { overlapping like roof shingles. It has } \\
\text { armour of horny scales that overlap like } \\
\text { shingles on a roof. At the slightest danger } \\
\text { the animal tucks its head into its stomach } \\
\text { and wraps itself into a ball with its muscu- } \\
\text { lar tail clasped tight around it. (Attenbor- } \\
\text { ough, David. 1979. Life on Earth. Boston, } \\
\text { MA: Little, Brown and Company.) }\end{array}$ \\
\hline \multirow[t]{2}{*}{$\begin{array}{l}\text { FORMING A } \\
\text { CABINET }\end{array}$} & $\begin{array}{l}\text { Display rack structure/ } \\
\text { joint }\end{array}$ & $\begin{array}{l}\text { Multiple joints allow circular move- } \\
\text { ment: crustaceans. Limbs of crustaceans } \\
\text { allow movement along several planes by } \\
\text { clustering two or three joints on a limb, } \\
\text { each working in a different direction. } \\
\text { (Attenborough, David. 1979. Life on Earth. } \\
\text { Boston, MA: Little, Brown and Company) }\end{array}$ \\
\hline & Access to sections & $\begin{array}{l}\text { The inner chambers of a nautilus allow for } \\
\text { buoyancy control via different mixtures } \\
\text { of stored air and water. The body of the } \\
\text { mollusc inhabits the very last of a spiral- } \\
\text { ling series of chambers inside the shell. By } \\
\text { filling the inner chambers with a mixture } \\
\text { of air and water, the nautilus achieves } \\
\text { perfect buoyancy, allowing it to rise effort- } \\
\text { lessly during its nightly migration from the } \\
\text { depths of the Pacific Ocean to the surface. } \\
\text { (Downer, J. 2002. Weird Nature: An Aston- } \\
\text { ishing Exploration of Nature's Strangest } \\
\text { Behaviour. Ontario: Firefly Books) }\end{array}$ \\
\hline \multirow[t]{3}{*}{$\begin{array}{l}\text { CREATING INTE- } \\
\text { RIOR ROOM }\end{array}$} & $\begin{array}{l}\text { Independent modules that } \\
\text { can pick and group }\end{array}$ & Cells, honeycomb \\
\hline & Release a component & $\begin{array}{l}\text { Hermit crab, release the shell to get a bigger } \\
\text { one }\end{array}$ \\
\hline & Reduced to basics & $\begin{array}{l}\text { Snail and turtle shells are reduced to the basic } \\
\text { casing to form a hollow volume }\end{array}$ \\
\hline
\end{tabular}

solutions for the product. Perhaps this is the most conceptual phase because of the definition of the product and how it will be developed.

The development usually requires a series of upgrading of the natural solution before it can be applied to the product. The table is used in the opposite direction, as shown in Table 4 by the green line, and the references found in nature are transformed and adapted to become a solution for key functions. These will be transformed into product requirements, adding value and differentiation and 
thus generating innovation. Analyzing the table, some natural references that are of interest for generating concepts can be seen. These concepts can arise from a single natural reference or from a combination of several. Concepts are described as a group of product specifications and the natural reference must be transformed into a design specification so that the biomimetic finding can be adapted to the key function.

\subsubsection{Phase 4. Conceptual design}

At this stage, the conceptual design for the chosen product is carried out. The research results obtained through functional analysis and biomimetic development are applied in a redesign or a new product concept, and then improvements are established. In this phase, possible solutions for conceptual design are proposed. The adaptation is performed through the development of ideas for the new product through sketches, drawings, texts, and other techniques that explain the concept. As an example, a backpack concept designed for people on long distance trips such as pilgrimages has been developed.

This backpack features a double entrance, located at the top and bottom (reference to mouth/ anus), which provides access to items stored inside. Elastic separations are also placed inside to create two different spaces within the bag (to create and adapt spaces) changing the size of these spaces according to user needs. Another feature of this bag is that the top is an area that can be inflated for use as support in times of rest. It also has a lightweight, extensible mobile accessory that unfolds over the user's head to protect from the sun or light rain (to provide some area or volume of protection). Some other ideas we have chosen for the backpack/suitcase are:

- Backpack that extends the base structure to allow for greater stability.

- Backpack consisting of pull-outs that once removed can be used as part of the closet of our house.

- Backpack that can be tied to vertical elements to enable other objects to hang from it.

- Backpack of elastic material casing to adapt to changes and needs of the contents.

- Suitcase with extensible structure that can be used as a coat rack.

\subsubsection{Phase 5. Detailed design}

This design phase develops the formalization of the product, similar to other design projects. The product is defined at a dimensional level, including production processes, material selection, etc. Since the projects were proposed at the conceptual level only, viability evaluation, knowing the state of the art and the possibility of applying the biomimetic results have not been developed in this work.

It should be mentioned that biomimetics can indeed be used as a tool in the final stages of the project, in the definition and development of new processes, and even in research and application of new materials. However, it falls outside the objectives and scope of this work.

\section{CONCLUSIONS}

The first conclusion concerns the level of innovation and the difficulty of solving key functions. The greater the innovation pursued, the greater the difficulty of finding a natural element to provide an answer to the more demanding key functions. Small improvements are easier to achieve as biomimetic references are easier to find [35]. Generic functions, in the first levels of functional analysis, have less interest and potential for innovation. The more specific and detailed the functions are, the more valuable they are and the more they contribute to product differentiation.

Innovation is sometimes incremental due to a simple but novel functional improvement. However, there are cases where the innovation is radical since project results finally produce new product concepts. Some of the projects had a few difficulties in the process of gathering relevant information 
to solve the key functions, so the need for a specialist such as a biologist is evident. Some biomimetic references were difficult to adapt as product requirements.

One natural solution may generate various design specifications, so more than one design solution may be established for further development and subsequent implementation.

Some natural references were found in invertebrates during the biomimetic research, but not all of them. This means that the relation between the exoskeleton and casings is not exclusive and that some key functions were not able to be based on the exoskeleton-casing relation.

It is difficult to obtain information and documentation about natural references. To overcome this difficulty, it is advisable to work with biologists who know the life forms, functions, behaviors, and characteristics that allow us to develop solutions to be applied in product design.

The methods used are exploratory, but it is necessary to normalize and standardize them so that the work may be more systematic and efficient.

\section{REFERENCES}

[1] Drachsler, K., Bionik - mit einer neuen Systematik schneller zu Innovationen. Interaktiv 1.2003.

[2] Steven, V., Ancas y palancas, mecánica natural y mecánica humana. Tusquets Editores: Barcelona, 2000.

[3] Wirkkala, T., available at http://www.scandinaviandesign.com/tapioWirkkala/index1.htm.

[4] Bar-Cohen, Y., Biomimetics: Reality, Challenges, and Outlook. Chapter in Biomimetics, biologically inspired technologies. CRC Press, Boca Raton, Florida, 2006.

[5] Viñolas i Marlet, J., Diseño ecológico: hacia un diseño y una producción en armonía con la naturaleza. Blume: Barcelona, 2005.

[6] Benyus, J., Biomimicry: innovation inspired by nature, Harper Collins Publishers Inc.: New York, 1997.

[7] Andrés-Hernando, Valencia Escobar., Experimentación objetiva, un instrumento para innovar. Encuentro Latinoamericano de Diseño, Acta $n^{\circ}$ 9, Universidad de Palermo: Buenos Aires, Argentina, 2010.

[8] Tassinari, R., El producto adecuado, práctica del análisis funcional. Barcelona: Marcombo, S.A., 1994.

[9] López, I., Relation between biomimetic and functional analysis in product design methodology. WIT Transactions on Ecology and the Environment, WIT Press, vol 138, 2010.

[10] Bogatyreva, O., Pahl, A.K., Adrian Bowyer, Julian Vincent, Data gathering for putting biology in TRIZ. Altshuller Institute 5th TRIZ Conference: Philadelphia, USA, 2003

[11] Vincent, J.F.V., Bogatyreva, O.A., Pahl, A.-K., Bogatyrev, N.R. \& Bowyer, A., Putting biology into TRIZ: a database of biological effects. Creativity Innov Manage, 14, pp. 66-72, 2005. doi: http://dx.doi.org/10.1111/j.1476-8691.2005.00326.x

[12] Bar-Cohen, Y., Biomimetics: mimicking and inspired-by biology. Proceedings of the SPIE Smart Structures Conference, SPIE: San Diego, CA., Vol. 5759-02, March 7-10, 2005.

[13] Steven, V., Comparative biomechanics, Life's physical world, Princeton University Press: New jersey, 2003.

[14] http://www.sharklet.com/ Sharklet Technologies, Inc @ 2010.

[15] Ferrater Mora, J., Diccionario de filosofía, Alianza Editorial: Madrid, 1979.

[16] Roshko, T., The pedagogy of bio-design: Methodology development. WIT Transactions on Ecology and the Environment, vol 138, 2010 WIT Press.

[17] Lodato, Franco., available at http://www.media.mit.edu/events/di-2004-10-22/lodato2004-1022.pdf

[18] The Biomimicry Institute, available at http://www.biomimicryinstitute.org/about-us/biomimicry-a-tool-for-innovation.html. 
[19] Di Bartolo, C., Strutture Naturali e Modelli bionici. Departament of Industrial Design, Istituto Europeo di Design: Milán, 1981.

[20] Songel, G., Estudio metodológico de la biónica aplicada al diseño industrial. Doctoral thesis. ETSI Industriales, Universidad Politécnica de Valencia, 1991.

[21] Lozano Crespo, Pedro María., El diseño natural: aproximación histórica, metodologías, aplicación y consecuencias. Doctoral thesis. Universidad Complutense de Madrid,1996.

[22] Matthias Gester. Biomimetics: strategies for product design inspired by nature - a mission to the Netherlands and Germany (Chapter 7). Background to biomimetics. DTI Global Watch Mission Report. January 2007.

[23] Milwich, M., Speck, T., Biomimetics and technical textiles: Solving engineering problems with the help of nature's wisdom. American Journal of Botany, 93(10), pp. 1455-1465, 2006. doi: http://dx.doi.org/10.3732/ajb.93.10.1455

[24] Helms, M., Biologically inspired design: process and products. Design Studies 30, pp. 606-622, 2009. doi: http://dx.doi.org/10.1016/j.destud.2009.04.003

[25] Wegst, U., available at http://www.materials.drexel.edu/faculty/wegst/.

[26] http://www-mech.eng.cam.ac.uk/cms/.

[27] Bhushan, B., Biomimetics: lessons from nature - an overview. Philosophical Transactions of the Royal Society A, 367, 2009.

[28] Vincent J., Bogatyreva O., Bogatyrev N., Bowyer A. \& Pahl, A., Biomimetics - its practice and theory. Interface Journal of Royal Society, 3(9), pp. 471-82, 2006. doi: http://dx.doi. org/10.1098/rsif.2006.0127

[29] Bogatyreva O.A., Pahl A-K. \& Vincent J.F.V., Enriching TRIZ with Biology: The Biological Effects database and implications for Teleology and Epistemology. ETRIA WORLD CONFERENCE-2002: Strasbourg, 6-8 November, pp.3-1-307.

[30] Gruber, P., Skin in architecture: towards bioinspired facades. WIT Transactions on Ecology and the Environment, vol 138, 2010 WIT Press.

[31] Gosztonyi, S., Challenging the engineering view: comparative analysis of technological and biological functions targeting energy efficient facade systems. WIT Transactions on Ecology and the Environment, vol 138, 2010 WIT Press.

[32] Buzan, T., El Libro de los Mapas mentales, Ediciones Urano: Barcelona (España), 1996.

[33] Kindlein Jr., W., Guanabara, A.S., Methodology for product design based on the study of bionics. Materials and Design 26, pp. 149-155, 2005. doi: http://dx.doi.org/10.1016/j.matdes.2004.05.009

[34] Vincent J., Biomimetic modelling. Philosophical Transactions of the Royal Society of London B, 358, pp. 1597-1603s, 2003. doi: http://dx.doi.org/10.1098/rstb.2003.1349

[35] Vincent, J.F.V., Stealing ideas from nature. Deployable Structures. ed. S Pellegrino, Springer, Vienna, pp. 51-58, 1997. 